\title{
EULAR evidence-based and consensus-based recommendations on the management of medium to high-dose glucocorticoid therapy in rheumatic diseases
}

\author{
N Duru, ${ }^{1}$ M C van der Goes, ${ }^{1}$ J W G Jacobs, ${ }^{1}$ T Andrews, $^{2}$ M Boers, ${ }^{3}$ F Buttgereit, ${ }^{4}$ \\ N Caeyers, ${ }^{5}$ M Cutolo, ${ }^{6}$ S Halliday, ${ }^{2}$ J A P Da Silva, ${ }^{7}$ J R Kirwan, ${ }^{8}$ D Ray, ${ }^{9}$ \\ J Rovensky, ${ }^{10} \mathrm{G}$ Severijns, ${ }^{5} \mathrm{R}$ Westhovens, ${ }^{11} \mathrm{~J}$ W J Bijlsma ${ }^{1}$
}

Handling editor Tore K Kvien

- Additional material is published online only. To view please visit the journal online (http://dx.doi.org/10.1136/ annrheumdis-2013-203249)

For numbered affiliations see end of article.

\section{Correspondence to} M C van der Goes, Department of Rheumatology \& Clinical Immunology (F02.127), University Medical Center Utrecht, PO Box 85500, 3508 GA Utrecht,

The Netherlands; m.c.vandergoes@umcutrecht.nl

ND and MC van der $G$ contributed equally to this article.

Received 8 January 2013 Revised 2 June 2013 Accepted 26 June 2013 Published Online First 19 July 2013
To cite: Duru N, van der Goes MC, Jacobs JWG, et al. Ann Rheum Dis 2013;72:1905-1913.

\section{ABSTRACT}

To develop recommendations for the management of medium to high-dose (ie, $>7.5 \mathrm{mg}$ but $\leq 100 \mathrm{mg}$ prednisone equivalent daily) systemic glucocorticoid (GC) therapy in rheumatic diseases.

A multidisciplinary EULAR task force was formed, including rheumatic patients. After discussing the results of a general initial search on risks of GC therapy, each participant contributed 10 propositions on key clinical topics concerning the safe use of medium to high-dose GCs. The final recommendations were selected via a Delphi consensus approach. A systematic literature search of PubMed, EMBASE and Cochrane Library was used to identify evidence concerning each of the propositions. The strength of recommendation was given according to research evidence, clinical expertise and patient preference.

The 10 propositions regarded patient education and informing general practitioners, preventive measures for osteoporosis, optimal GC starting dosages, risk-benefit ratio of $\mathrm{GC}$ treatment, $\mathrm{GC}$ sparing therapy, screening for comorbidity, and monitoring for adverse effects. In general, evidence supporting the recommendations proved to be surprisingly weak. One of the recommendations was rejected, because of conflicting literature data.

Nine final recommendations for the management of medium to high-dose systemic GC therapy in rheumatic diseases were selected and evaluated with their strengths of recommendations. Robust evidence was often lacking; a research agenda was created.

\section{INTRODUCTION}

Glucocorticoids (GCs) are a cornerstone in the treatment of rheumatic diseases for many decades. Detailed information on the capacity of GCs to retard the progression of joint damage in rheumatoid arthritis (RA) has been published. ${ }^{1-7}$ GCs are also used, often in higher dosages, for many other rheumatic diseases such as polymyalgia, lupus and vasculitis. Medium/high-dose GC therapy (ie, $>7.5 \mathrm{mg}$ but $\leq 100 \mathrm{mg}$ prednisone equivalent daily) generates non-genomic effects next to genomic effects, which occur already at lower dosages, indicating that the risk-benefit profile for these higher dosages might be different from that for low dosages. $^{8}$ General recommendations on the management of GC therapy have been developed by the EULAR task force on GC therapy, ${ }^{9}$ but these were mainly based on evidence and experience with low-dose GC therapy (ie, $\leq 7.5 \mathrm{mg}$ prednisone equivalent daily). Proper advice on balancing advantages and disadvantages of medium/high-dose GC therapy is lacking. Therefore, this task force set out to develop recommendations for the use and management of systemic medium/high-dose GC therapy in rheumatic diseases.

\section{METHODS}

\section{Participants}

The EULAR task force on GC therapy is a multidisciplinary committee consisting of 16 experts from 7 European countries ( 8 rheumatologists, 1 endocrinologist, 1 rheumatologist/epidemiologist, 4 rheumatic patients as patients' representatives and 2 research fellows). The objective was to formulate 10 recommendations on the management of medium/highdose systemic GC therapy in rheumatic diseases by identifying and critically appraising evidence in the literature. The strength of each recommendation was evaluated.

\section{Experts' consensus and Delphi rounds}

As a first step, a general systematic literature search was performed aiming at identifying prospective follow-up studies in which medium/high-dose GC therapy was administered systemically. This search was not limited to rheumatic diseases (see online supplementary appendix 1 for details on this search). We used the databases PubMed, EMBASE and Cochrane Library; search results on adverse events (AEs) were expressed in events per patient year and odds ratios (ORs) (not corrected for disease activity or comorbidity) and summarised in tables (see online supplementary appendix 2), using the software Comprehensive Meta Analysis V2. The results were presented at the first group meeting to initiate group discussions identifying important topics. After the first meeting, each task force member independently formulated 10 propositions related to management of medium/highdose GC use in rheumatic diseases. The Delphi technique was used to reach consensus on the propositions as follows. The initial propositions were listed and overlapping propositions were amalgamated. The list was returned to the members with the request to select the 10 most important 
propositions in this first round. A proposition was accepted if over three-quarters of the members selected it in the first round, two-thirds in the second round, and half in the third and fourth rounds. A proposition was removed if it was selected by onequarter of the participants or less in the first round, one-third or less in the second round, and half or less in the third and fourth rounds. After 4 rounds, 10 propositions of which the text had been optimised by an English native speaker remained and were agreed upon by all participants.

\section{Systematic literature search of the 10 propositions}

After agreement on 10 propositions, additional propositionspecific searches were performed using PubMed, EMBASE and Cochrane Library by two research fellows (see online supplementary appendix 3 for details on inclusion and exclusion per search). Results of the different databases were combined and duplicates were excluded; issues regarding inclusion or exclusion of articles were resolved by discussion and consensus. Articles evaluating the value of a recommendation were selected and in case of lack of evidence, circumstantial evidence was looked for. References of articles found were screened for additional evidence.

\section{Categorising evidence and strength of recommendations}

The quality of evidence based on study design was categorised according to the EULAR hierarchy (table 1). ${ }^{10}$

After the proposition-specific literature searches, evidence regarding each of the recommendations was subjected to group discussion; the final recommendations were approved by all members. For each proposition, the strength of recommendation (SOR) was graded using an A-E ordinal scale ( $\mathrm{A}=$ fully recommended, $\mathrm{B}=$ strongly recommended, $\mathrm{C}=$ moderately recommended, $\mathrm{D}=$ weakly recommended and $\mathrm{E}=$ not recommended) and a visual analogue scale (VAS, $0-100 \mathrm{~mm}, 0=$ no agreement and $100=$ maximal agreement). The members were asked to consider both the quality of evidence presented and their own clinical experience while grading. For each proposition, the mean VAS and $95 \% \mathrm{CI}$, and the percentage of strongly to fully recommended (A-B) propositions were calculated. This grading method has not been fully evaluated, but is, in our view, valuable to give SOR for recommendations which cannot be or have not been assessed in randomised controlled trials (RCT); SOR has been used for other EULAR recommendations too. ${ }^{9} 11$

During the meetings, members were asked to discuss items which should be the focus of future research. These items were combined into a research agenda.

\section{RESULTS}

\section{General literature search}

The general search on AEs of medium/high-dose GCs (see online supplementary appendix 1) yielded a total of 1104 hits

Table 1 The level of evidence based on study design ${ }^{10}$

\section{Level of evidence}

I-A Meta-analysis of randomised controlled trials

I-B Randomised controlled trial

II-A Controlled study without randomisation

II-B Quasiexperimental study

III Descriptive study (comparative, correlation, case-control)

IV Expert committee report/opinion and/or clinical opinion of respected authority
(461 in PubMed, 427 in EMBASE and 216 in Cochrane database), reduced to 916 hits excluding duplicates. Of these studies, only 53 met the inclusion criteria. ${ }^{2} 3712-61$ Online supplementary appendix 2 gives an overview of the estimated incidence of different AEs derived from the studies reporting on dichotomous $\mathrm{AE}$ outcomes, or mean values derived from the studies reporting mean outcomes. Major limitations of these search results are the lack of sufficient GC-naive control groups, the incompleteness of defining and reporting AEs, and the probability of selective reporting of some AEs.

\section{Experts' opinion approach}

After discussing the results of the general literature search, the Delphi exercise was initiated. At start, 126 (partly overlapping) propositions were produced, and after four anonymous Delphi rounds, 10 propositions were agreed upon, of which one was rejected after evaluating the available evidence (table 2 ).

\section{RECOMMENDATIONS}

The recommendations can be classified in the main issues of education and prevention, dosing and the risk-benefit ratio, and monitoring.

\section{Explain to patients (and their family and/or carers, including healthcare professionals) the aim of medium/high-dose GC treatment and the potential risks associated with such therapy}

The goals of this education are to correctly inform especially patients about GC therapy, reassuring them if there would be unfounded worries about the treatment, increasing vigilance for AEs and improving adherence to treatment. The search retrieved one cross-sectional and one retrospective study in rheumatic diseases evaluating the need for informing patients on the benefits and risks of GC treatment. ${ }^{62} 63$ The first study showed that worries about potential AEs-often caused by ineffective communication-may lead to termination of DMARD therapy (among which GC therapy). ${ }^{62}$ A study on patients' views on GC therapy indicated that information should be given in a structured manner in small steps over time. ${ }^{63}$

Circumstantial evidence: RCTs in asthma and chronic obstructive pulmonary disease often showed better adherence to (inhaled) GC treatment after patient education, ${ }^{64-71}$ and fewer exacerbations and reduced hospitalisation in some but not all studies. ${ }^{72-74}$ An RCT focused on GC-induced osteoporosis education in patients with different diseases showed improved calcium intake after verbal and written information given by pharmacists. ${ }^{75}$ This is in line with other studies showing that patients' knowledge about GCs is best served by written information combined with verbal instructions. ${ }^{75-78}$ In educating, items such as communicative skills (eg, the use of non-technical language, adapted to the patient's education level) and cultural aspects are important. ${ }^{62} 79-82$

To guide education on AEs of GCs, those that concern patients and rheumatologists most are shown in table $3 .^{63}$

\section{Discuss measures to mitigate such risks, including diet, regular exercise and appropriate wound care}

The risks of some AEs have been proven to be mitigated or counterbalanced by lifestyle interventions. A prospective cohort study in RA with $72 \%$ of patients on GC therapy showed that moderate physical activity reduced the risk of osteopenia. ${ }^{83}$ Moreover, a cross-sectional study in RA with most patients on GCs showed a positive association between quadriceps muscle strength and femoral neck bone mineral density (BMD). ${ }^{84}$ 
Table 2 The recommendations with strength of recommendation and level of evidence

\begin{tabular}{|c|c|c|c|c|}
\hline & & \multicolumn{2}{|l|}{ SOR } & \multirow[b]{2}{*}{ LoE } \\
\hline \multicolumn{2}{|c|}{ Proposition } & $\begin{array}{l}\text { VAS; mean } \\
(95 \% \mathrm{Cl})\end{array}$ & $A+B \%$ & \\
\hline \multicolumn{5}{|c|}{ Education and prevention } \\
\hline 1 & $\begin{array}{l}\text { Explain to patients (and their family and/or carers, including healthcare professionals) the aim of medium/high-dose GC } \\
\text { treatment, and the potential risks associated with such therapy }\end{array}$ & 91 (81 to 101$)$ & 100 & III \\
\hline 2 & Discuss measures to mitigate such risks, including diet, regular exercise and appropriate wound care & 75 (57 to 93$)$ & 75 & III/IV \\
\hline 3 & Patients with, or at risk of, GC-induced osteoporosis should receive appropriate preventive/therapeutic interventions & $91(84$ to 99$)$ & 100 & I-A \\
\hline 4 & $\begin{array}{l}\text { Patients and the patients' treatment teams should receive appropriate, practical advice on how to manage with GC-induced } \\
\text { hypothalamic-pituitary-adrenal axis suppression }\end{array}$ & $84(67$ to 101$)$ & 92 & IV \\
\hline 5 & $\begin{array}{l}\text { Provide an accessible resource to promote best practice in the management of patients using medium/high-dose GCs to } \\
\text { general practitioners }\end{array}$ & 80 (69 to 91$)$ & 75 & IV \\
\hline \multicolumn{5}{|c|}{ Dosing/risk-benefit } \\
\hline 6 & $\begin{array}{l}\text { Before starting medium/high-dose GC treatment consider comorbidities predisposing to AEs. These include diabetes, glucose } \\
\text { intolerance, cardiovascular disease, peptic ulcer disease, recurrent infections, immunosuppression, (risk factors of) glaucoma } \\
\text { and osteoporosis. Patients with these comorbidities require tight control to manage the risk/benefit ratio }\end{array}$ & 85 (76 to 94$)$ & 83 & IV \\
\hline 7 & Select the appropriate starting dose to achieve therapeutic response, taking into account the risk of undertreatment & 85 (76 to 95$)$ & 92 & I-A/IV \\
\hline 8 & $\begin{array}{l}\text { Keep the requirement for continuing } \mathrm{GC} \text { treatment under constant review, and titrate the dose against therapeutic response, } \\
\text { risk of undertreatment and development of AEs }\end{array}$ & $82(72$ to 94$)$ & 92 & IV \\
\hline 9 & If long-term medium/high-dose GC therapy is anticipated to be necessary, actively consider GC-sparing therapy & REJECTED & & \\
\hline \multicolumn{5}{|c|}{ Monitoring } \\
\hline 10 & $\begin{array}{l}\text { All patients should have appropriate monitoring for clinically significant AEs. The treating physician should be aware of the } \\
\text { possible occurrence of diabetes, hypertension, weight gain, infections, osteoporotic fractures, osteonecrosis, myopathy, eye } \\
\text { problems, skin problems and neuropsychological AEs }\end{array}$ & 85 (79 to 92$)$ & 75 & IV \\
\hline
\end{tabular}

Circumstantial evidence: Physical exercise is in general effective to prevent osteoporosis, ${ }^{85-87}$ and is recommended in recent guidelines on prevention of GC-induced osteoporosis. ${ }^{88}$ Benefits of exercise training regarding the risk of GC-induced osteoporosis have also been found in organ transplants and pulmonary disease patients. ${ }^{89-93}$ Other lifestyle advices for the prevention of osteoporosis include stopping of smoking, ${ }^{94}$ limiting alcohol intake, ${ }^{94}$ maintaining an adequate dietary calcium intake, ${ }^{95} 96$ training muscles for strength, ${ }^{97}$ and performing weight-bearing exercises on a daily basis. ${ }^{88}$

Although recommendations on diet and physical activity are broadly endorsed for the general population to prevent cardiovascular disease ${ }^{8586}$ which occurs in a higher frequency in patients with inflammatory rheumatic diseases compared with the general population, ${ }^{98} 99$ no supportive information on diet and physical activity mitigating the GC-induced risk of cardiovascular disease, increased appetite, and weight gain was found. Evidence on increasing awareness of wounds or applying appropriate wound care in the context of GC therapy for prevention of wound complications was lacking. Nevertheless, GC-induced skin atrophy and increased risk of infection provide a rationale to discuss prevention and good wound care. $^{100} 101$

\section{Patients with, or at risk of, GC-induced osteoporosis should receive appropriate preventive/therapeutic interventions}

Generally, all patients starting medium/high-dose GC therapy are at risk of developing osteoporosis. Several meta-analyses showed efficacy of calcium, (active) vitamin D and bisphosphonates in preventing and treating GC-induced osteoporosis. ${ }^{96}$ 102-105 Preventive therapy with calcium and vitamin D should be started, because GCs via inhibition of intestinal calcium absorption and renal tubular calcium reabsorption impair bone metabolism.
Additionally, in general, bisphosphonates are indicated. Guidelines on indications and choices for specific drugs differ somewhat between countries.

Oral GC treatment with $>5 \mathrm{mg}$ prednisone daily can lead to a reduction in BMD and a rapid dose-dependent increase in the risk of fracture. ${ }^{106} 107$ However, in many studies on GC-induced osteoporosis, it is ignored that GCs are usually prescribed for inflammatory diseases which themselves have a negative impact on BMD. For instance, in RA, it has been shown that BMD loss may develop in absence of GC therapy, especially in the first months of disease. $^{108} 109$ Correlations of loss of BMD with parameters of inflammation have also been found in other studies. ${ }^{110-113}$ Therefore, the independent contribution of GCs to this problem may be lower than estimated. Several algorithms have been developed to refine the estimate of the risk of fractures for individual patients, such as the FIGS (fracture risk in GC-induced osteoporosis score) which includes the GC dosage taken, and FRAX (Fracture Risk Assessment), ${ }^{88} 114115$ for which also adjustments have been suggested for GC dosages $>7.5 \mathrm{mg}$ prednisone equivalent daily. 116117

\section{Patients and the patients' treatment teams should receive appropriate, practical advice on how to manage with GC-induced hypothalamic-pituitary-adrenal axis suppression}

Risk of adrenal insufficiency is considered to be present if GC therapy is stopped suddenly in chronic users, and in acute situations such as acute illnesses and surgical interventions. We found two systematic reviews on the value of additional GC supplementation in the perioperative setting. ${ }^{118} 119$ One review, mainly on patients with organ transplants, concluded that patients on GCs do not require perioperative stress doses if they 
Table 3 Risks of GC-related AEs based on placebo-controlled studies and studies without control group*

\begin{tabular}{|c|c|c|c|}
\hline \multicolumn{4}{|l|}{ Placebo-controlled studies } \\
\hline$A E$ & Dose range and application & Events/100 patient-years for GC users & Events/100 patient-years for GC-naive patients \\
\hline Osteoporosis & $\begin{array}{l}\text { chronic medium dose } \\
\text { intramuscular }\end{array}$ & $\begin{array}{l}16 \\
2\end{array}$ & $\begin{array}{l}3 \\
0\end{array}$ \\
\hline $\begin{array}{l}\text { Cardiovascular disease (ie, myocardial } \\
\text { infarction) }\end{array}$ & $\begin{array}{l}\text { chronic medium dose } \\
\text { step-down } \\
\text { intramuscular }\end{array}$ & $\begin{array}{l}0-1 \\
1 \\
0-1\end{array}$ & $\begin{array}{l}0-1 \\
0 \\
0-1\end{array}$ \\
\hline Diabetes & $\begin{array}{l}\text { chronic medium dose } \\
\text { intramuscular }\end{array}$ & $\begin{array}{l}0-3 \\
1\end{array}$ & $\begin{array}{l}0-1 \\
0\end{array}$ \\
\hline Weight gain & intramuscular & 0 & 1 \\
\hline Renal dysfunction & $\begin{array}{l}\text { chronic medium dose } \\
\text { step-down }\end{array}$ & $\begin{array}{l}1-6 \\
0-17\end{array}$ & $\begin{array}{l}0 \\
0-1\end{array}$ \\
\hline Peptic ulcer disease & chronic medium dose & $1-4$ & $0-2$ \\
\hline Hypertension & $\begin{array}{l}\text { chronic medium dose } \\
\text { step-down } \\
\text { intramuscular }\end{array}$ & $\begin{array}{l}3-28 \\
0 \\
4\end{array}$ & $\begin{array}{l}0-19 \\
0 \\
1\end{array}$ \\
\hline \multicolumn{4}{|l|}{ Studies without control group } \\
\hline$A E$ & Dose range and application & Events/100 patient-years for GC users & \\
\hline Osteoporosis & $\begin{array}{l}\text { chronic medium dose } \\
\text { chronic high } \\
\text { step-down }\end{array}$ & $\begin{array}{l}1-3 \\
2 \\
0-23\end{array}$ & \\
\hline $\begin{array}{l}\text { Cardiovascular disease (ie, myocardial } \\
\text { infarction) }\end{array}$ & $\begin{array}{l}\text { chronic medium dose } \\
\text { chronic high }\end{array}$ & $\begin{array}{l}0-1 \\
0\end{array}$ & \\
\hline Diabetes & $\begin{array}{l}\text { chronic medium dose } \\
\text { chronic high } \\
\text { step-down }\end{array}$ & $\begin{array}{l}0-13 \\
1 \\
0-18\end{array}$ & \\
\hline Weight gain & $\begin{array}{l}\text { chronic medium dose } \\
\text { step-down }\end{array}$ & $\begin{array}{l}0-63 \\
3-21\end{array}$ & \\
\hline Renal dysfunction & $\begin{array}{l}\text { chronic medium dose } \\
\text { step-down }\end{array}$ & $\begin{array}{l}9-13 \\
5-40\end{array}$ & \\
\hline Peptic ulcer disease & $\begin{array}{l}\text { chronic medium dose } \\
\text { step-down }\end{array}$ & $\begin{array}{l}0-1 \\
0\end{array}$ & \\
\hline Hypertension & $\begin{array}{l}\text { chronic medium dose } \\
\text { chronic high } \\
\text { step-down }\end{array}$ & $\begin{array}{l}0-63 \\
2 \\
0-38\end{array}$ & \\
\hline
\end{tabular}

${ }^{*} \mathrm{AEs}$ that concern patients and rheumatologists most. ${ }^{63}$ These AEs should be discussed with patients when GC therapy is initiated.

Events per 100 patient years, based on information gained with the general literature search on medium/high-dose GC treatment, are given in this table (detailed information on all AEs reported is given in the tables of online supplementary appendix 2).

$A E$, adverse event; GC, glucocorticoid.

continue their daily dose between 5 and $16 \mathrm{mg}$ prednisone ${ }^{118}$; the other concluded that data was too limited to support or refute perioperative stress doses. ${ }^{119}$

Circumstantial evidence: Although hypothalamic-pituitaryadrenal axis suppression may vary greatly from person to person, it should be anticipated in any patient receiving more than $7.5 \mathrm{mg}$ of prednisolone equivalent daily for more than 3 weeks. ${ }^{120}$ The risk cannot be excluded by alternate day GC therapy, and remains difficult to predict. ${ }^{121} 122$ On the basis of these data, to be cautious, adequate GC replacement is recommended by the task force in acute situations for patients on chronic medium/high-dose GC treatment; GC therapy should not be stopped without tapering. Evidence supporting superiority of a specific replacement or stress scheme is not available. Pragmatically, one could choose to increase the dosage for 3 days, or, depending on the clinical situation, switch to intravenous hydrocortisone (eg, starting two times $25 \mathrm{mg}$ daily for patients on $10 \mathrm{mg}$ prednisone daily, or three times $50 \mathrm{mg}$ daily for patients on high-dose GC therapy). The need for stress schemes with higher dosages has not been proven, although in some situations they might be considered. Patients and their treatment teams, including the general practitioner, should be informed on the risk of adrenal insufficiency, and should know how to prevent it.

\section{Provide an accessible resource to promote best practice in the management of patients using medium/high-dose GCs to general practitioners}

General practitioners frequently prescribe GC therapy, for example, to treat polymyalgia, ${ }^{123}$ and are likely to be consulted for problems with GCs. A cross-sectional study among general practitioners showed insufficient guidance on GC use for patients with exacerbations of chronic obstructive pulmonary disease, and insufficient knowledge on how to take comorbidity into account. ${ }^{124}$ Thus, although our search yielded no data on an accessible resource to inform general practitioners on the management of medium/high-dose GC therapy, such a source makes sense. This could be a website on the benefits and risks of GC treatment, advising how to manage intercurrent illnesses and acute situations. Ultimately these recommendations could be included in general practitioner guidelines. We do not suggest that general practitioners should manage all patients on medium/high-dose GC 
treatment, but they should be able to adequately respond when consulted with questions regarding this therapy.

\section{Before starting medium/high-dose GC treatment, consider comorbidities predisposing to AEs. These include diabetes, glucose intolerance, cardiovascular disease, peptic ulcer disease, recurrent infections, immunosuppression, (risk factors of) glaucoma and osteoporosis. Patients with these comorbidities require tight control to manage the risk/ benefit ratio}

All patients with inflammatory rheumatic diseases require monitoring of comorbidities as part of good clinical practice. There are no studies evaluating the benefits of screening for comorbidities especially before starting GC therapy. However, as several individual comorbidities are also known as (risk factors for) AEs of GC therapy, identification and (preventive) treatment can be expected to diminish the frequency and severity of AEs. The reporting of GC-related AEs in the literature has been studied, ${ }^{9} 125$ but these reviews mostly excluded long-term highdose treatment. Some studies showed that the frequency of occurrence of specific AEs increased with higher doses of GC therapy. ${ }^{100126127}$ These are arguments to pay specific attention to comorbidities predisposing to AEs before starting medium/ high-dose GC treatment. In case comorbidities are present, tight control (ie, more intensive monitoring and adjusting medication, if needed) is recommended.

Diabetes and glucose intolerance: In RA, impaired insulin sensitivity has been reported and associated with increased disease activity. ${ }^{128} 129$ A recent study showed that a 1-week exposure to high-dose GCs did not deteriorate the metabolic state in active RA. ${ }^{130}$ Chronic treatment with $10 \mathrm{mg}$ prednisone daily did not lead to higher glucose levels or increased incidence of diabetes. ${ }^{7}$ However, worsening of pre-existent diabetes has been described in $\mathrm{RA},{ }^{131}$ and an incidence of $12.6 \%$ of GC-induced diabetes has been found among lupus patients after a mean of 34 days after starting high-dose GC therapy. ${ }^{132}$ So, although GC therapy could be a safe treatment option in this regard for most patients, especially for those with very active disease on low/medium dosages, glucose monitoring before start of therapy and during therapy is advised, due to individual differences in glucose tolerance and response to GCs.

Cardiovascular disease: Retrospective analyses, not corrected for disease severity, showed an increased occurrence of cardiovascular disease in rheumatoid factor-positive RA patients. ${ }^{99}$ Cardiovascular parameters (eg, blood pressure, lipids) can be negatively influenced by inflammatory diseases, and intensive treatment with GCs might mitigate or even reverse this negative influence rather than worsen it. ${ }^{61}{ }^{133-136}$ GC therapy has been related to decreases in total and high-density lipoprotein cholesterol, but net results on the atherogenic index are conflicting. ${ }^{61} 133136$ The effect on blood pressure is also uncertain. ${ }^{134} 135$ Therefore, assessment of cardiovascular risk factors is not only important for patients starting GCs, but for all patients with inflammatory diseases. ${ }^{137}$ Pretreatment screening may reveal the need for preventive interventions, and will provide baseline values to which the follow-up measurements can be related.

Peptic ulcer disease: GC use is associated with an increased risk for peptic ulcer disease, especially when combined with non-steroidal anti-inflammatory drugs (NSAIDs). ${ }^{126} \quad 138 \quad 139$ However, GC use can lead to reduced NSAID use. ${ }^{140}$ Patients should be informed and appropriate preventive measures (eg, prescriptions of proton pump inhibitors) should be taken if patients have risk factors for peptic ulcer disease, such as concomitant NSAID use, an inflammatory disease and high age.
Recurrent infections and immunosuppression: Although RCTs with GCs are often reporting no significant difference in occurrence of infections, ${ }^{2} 372836$ GC therapy was associated with increased infection risk in patients with RA in cohort and casecontrol studies. ${ }^{101}$ 141-143 Moreover, other immunosuppressive treatments simultaneously given can further elevate the risk. These data suggest that awareness of the risk of infections before and during GC treatment is needed. One should realise that GC treatment may affect the performance of screening tests for infections, such as the QuantiFERON gold in-tube test and the tuberculin skin test, ${ }^{144}$ and that recommendations for vaccination in patients with inflammatory rheumatic diseases have been developed. ${ }^{145}$

Glaucoma: GCs can increase intraocular pressure or worsen preexisting glaucoma. ${ }^{146}$ The risk of glaucoma is dose dependent. ${ }^{147}$ Patients should be asked for high myopia, presence of diabetes, or a family history of glaucoma. In case any of these factors is present, screening should be performed by an ophthalmologist. ${ }^{148}$

Osteoporosis: see recommendation 2 and 3.

\section{Select the appropriate starting dose to achieve therapeutic} response, taking into account the risk of undertreatment

The search revealed one systematic review on the treatment of polymyalgia looking into starting dosages up to $100 \mathrm{mg}$ prednisone equivalent daily, in which the scarcity of RCTs and the heterogeneity of studies were emphasised. ${ }^{149}$ However, the conclusion was that remission can be achieved with a starting dose of $15 \mathrm{mg}$ prednisone daily in most patients.

In giant cell arteritis (GCA), higher initial doses are often used (mostly 40-60 mg prednisone daily). Compared with these doses, the benefits of pulse treatment $(\geq 250 \mathrm{mg}$ prednisone equivalent) were significant in one $\mathrm{RCT}^{59}$ but not in another RCT. $^{23}$ The different study designs applied, the limited number of patients included, the different patient selection criteria, the different doses and routes of GC administration used and the varying follow up measurements performed, preclude to recommend a specific GC regimen for GCA. ${ }^{150}$

For no other rheumatic diseases have specific starting dosages been tested in RCTs. In general, the appropriate starting dose will depend on (the severity of) the disease, the goals of treatment and characteristics of the individual patient, including age, comorbidities and body weight, all influencing pharmacokinetics, pharmacodynamics and sensitivity for GCs. ${ }^{151}$

\section{Keep the requirement for continuing GC treatment under constant review, and titrate the dose against therapeutic response, risk of undertreatment and development of AEs} There is no literature on how to weigh doses, benefits and risks of GC therapy. This again will depend on the disease, indication and goals of treatment, initial response to treatment, development of AEs, and individual patient characteristics. It is not possible, with the evidence currently available, to provide clear guidance on this important and difficult task. Nevertheless, it has face validity to keep the dose as low as needed to achieve therapeutic effect in each individual patient. Specific treatment goals may require different GC regimes or different periods of treatment. For example, for achieving joint protective effects in early RA, evidence only exists for a GC treatment duration of at least 6 months, ${ }^{6}$ and a maximum of 2 years. ${ }^{14-7}$ Rapid tapering of GC therapy has been associated with higher rates of relapse in polymyalgia and more frequent unsuccesfull cessation of therapy. ${ }^{149}$ Regular checks of the requirement for GC therapy are needed for appropriate decisions on continuing, increasing or tapering dosages, because patient and disease conditions will change over time. 
Rejected: If long-term medium/high-dose GC therapy is anticipated to be necessary, actively consider GC-sparing therapy

Other immunomodulatory drugs, including biologicals, are often added to GC therapy to improve efficacy; if these drugs enable decreasing the dose or duration of GC therapy, they can be seen as GC-sparing agents. Among all studies, 2 level 1A articles on 'GC-sparing properties of other medication', that is, use of other agents to decrease the cumulative GC dose, were retrieved by the literature search. ${ }^{149} 152$ These papers were on GC-sparing effect solely in polymyalgia and GCA.

A systematic review on GC-sparing agents in polymyalgia ${ }^{149}$ included five RCTs investigating the possibility of substituting partially or totally the GC by methotrexate, ${ }^{22} 43153$ azathioprine, ${ }^{154}$ or infliximab. ${ }^{49}$ Two RCTs of this review showed that GCs doses could be reduced, ${ }^{22} 153$ two showed no sparing properties, ${ }^{43}{ }^{49}$ and one RCT showed GC dose reduction with azathioprine, but at the cost of high rates of withdrawal due to AEs. ${ }^{154} \mathrm{~A}$ meta-analysis in GCA concluded that adjunctive treatment with methotrexate lowers the risk of relapse and reduces exposure to GCs, ${ }^{152}$ while the results of the individual RCTs were conflicting. ${ }^{29} 4560$ Other RCTs with infliximab and cyclosporine in GCA did not show GC-sparing effects of these drugs, ${ }^{155} 156$ while etanercept was effective as GC-sparing agent in a small group of patients. ${ }^{157}$

Because these results on GC-sparing effects in polymyalgia and GCA are conflicting, the task force decided to reject this recommendation.

\section{All patients should have appropriate monitoring for clinically significant AEs. The treating physician should be aware of the possible occurrence of diabetes, hypertension, weight gain, infections, osteoporotic fractures, osteonecrosis, myopathy, eye problems, skin problems and neuropsychological AEs}

Since we found no evidence showing the effectiveness of monitoring, this recommendation is based on expert opinion only. For several AEs it has been proven that the occurrence depends on dose and duration of GC treatment, ${ }^{100} 126127$ so these factors should dictate what to monitor and how often. Monitoring is useful for preventable and treatable AEs especially if the AE is common (ie, low number needed to screen), the $\mathrm{AE}$ is severe or has a significant impact on quality of life, the cost of monitoring is low, and monitoring is feasible in clinical practice. ${ }^{148}$ Monitoring and prevention of (extra-articular) complications should-as part of good clinical practice-be performed in all patients with inflammatory diseases, whether using GCs or not.

\section{DISCUSSION}

These recommendations as guidance for daily practice are an attempt to promote safer use of medium/high-dose GCs in rheumatic diseases. The order of recommendations in this paper does not reflect importance or the level of evidence, but reflects the logical order in patient management.

Strengths of this paper are the broad participation of experts and patients, the use of research data however limited, and the use of an evidence-based format. Many text books and review articles provide recommendations on the use of GCs based on traditional practice and widely held beliefs that developed before adequate attention was paid to the quality of the evidence base. Here, as far as possible, we have avoided their automatic reiteration or the expression of our own beliefs, but have concentrated on what can be concluded from published studies.
Sound evidence is scarce. To some readers this will have produced less clear-cut and less comprehensive recommendations than they would have liked to get. This reflects changes in the approach to evidence-based medical practice. This paper also has limitations. First, the literature searches may have been too specific, thus missing relevant studies. Second, systematic reviews and RCTs are considered as highest quality evidence, but these studies are often focused on treatment efficacy. ${ }^{158} 159$ They have not been powered or designed to assess toxicity or long-term efficacy, and therefore, uncertainty of the true incidence and relevance of several AEs remains. Had these studies been graded for study quality based on their analyses of AEs, study quality probably would have been graded much lower. In all observational (ie, not randomised) studies, the problem of channeling bias/confounding by indication severely impairs or precludes the possibility of drawing conclusions. In other words: in general, the more severe the inflammatory status of patients, the higher the chance of starting GCs; however, due to the design, no conclusion on causality between therapy and negative effects or events can be drawn. Third, rather heterogeneous studies (eg, different diseases, ages, GC schemes and cotreatment) have been pooled to get at least an overall impression of $\mathrm{AE}$ occurrence (see online supplementary appendix 2). In these studies, almost all patients with inflammatory rheumatic diseases (except those with polymyalgia or GCA) have been treated with multiple agents, which obviously impairs studying the risk-benefit ratio of GCs separately. Finally, these recommendations address issues on GC therapy from a general perspective, that is, not disease specific or patient specific. However, appropriate management varies considerably for different indications for such treatment, as discussed for starting doses with recommendation 7 . Next, individual patient characteristics may warrant dose adaptations or more frequent monitoring for AEs.

\section{Research agenda}

The paucity of data we found illustrates that crucial knowledge on cellular mechanisms of GC and on wanted and unwanted clinical effects of medium/high-dose GCs is missing. A robust database on the AE profile of medium/high-dose GCs is urgently needed to inform patients and their doctors with precise definitions of AEs, and standardised reporting both on the group level (eg, in means) and on the patients' level (eg, percentages). All future studies evaluating medium/high-dose GC therapy should systematically check for and register all AEs in this way, indexed to the type of GC, its regimen, duration of treatment and cumulative dose. This would enable the investigation of the influence of patient-related factors, such as gender, age, weight, comorbidity and co-medication. Also, research on timing of GC administration and perceptions and misconceptions of patients and healthcare providers is needed. Alternative therapies to GCs and GC-sparing therapies, including biologicals, need to be evaluated in well-designed trials.

\section{Author affiliations}

${ }^{1}$ Department of Rheumatology \& Clinical Immunology, University Medical Center Utrecht, Utrecht, The Netherlands

${ }^{2}$ EULAR Social Leagues Patients' Representative, Bristol, UK

${ }^{3}$ Department of Clinical Epidemiology and Biostatistics, VU University Medical Centre, Amsterdam, The Netherlands

${ }^{4}$ Department of Rheumatology and Clinical Immunology, Charité Universitätsmedizin Berlin, Berlin, Germany

${ }^{5}$ EULAR Social Leagues Patients' Representative, Leuven, Belgium

${ }^{6}$ Research Laboratory and Division of Rheumatology, Department of Internal Medicine, University of Genova, Genova, Italy

${ }^{7}$ Department of Reumatologia, Centro Hospitalar e Universitário de Coimbra, Coimbra, Portugal 
${ }^{8}$ University of Bristol Academic Rheumatology Unit, Bristol Royal Infirmary, Bristol, UK

${ }^{9}$ Centre for Endocrinology and Diabetes, Institute for Human Development, University of Manchester, and Manchester Academic Health Sciences Centre, Manchester, UK

${ }^{10}$ National Institute of Rheumatic Diseases, Piest'any, Slovakia

${ }^{11}$ Rheumatology, Department of Development and Regeneration, Neuro-musculoskeletal Research Unit, KU Leuven, Leuven, Belgium

Contributors We declare that all authors included on this paper fulfil the criteria of authorship.

Funding The activities of this task force are financially supported by EULAR.

Competing interests JWGJ was a member of speakers' bureau of Mundipharma International Limited and received travel expenses and an honorarium for his contributions.

Patient consent No.

Provenance and peer review Not commissioned; externally peer reviewed.

\section{REFERENCES}

1 Kirwan JR. The effect of glucocorticoids on joint destruction in rheumatoid arthritis. The Arthritis and Rheumatism Council Low-Dose Glucocorticoid Study Group. N Engl J Med 1995;333:142-6.

2 Boers M, Verhoeven AC, Markusse HM, et al. Randomised comparison of combined step-down prednisolone, methotrexate and sulphasalazine with sulphasalazine alone in early rheumatoid arthritis. Lancet 1997;350:309-18.

3 van Everdingen AA, Jacobs JW, Siewertsz, van Reesema DR, et al. Low-dose prednisone therapy for patients with early active rheumatoid arthritis: clinical efficacy, disease-modifying properties, and side effects: a randomized, double-blind, placebo-controlled clinical trial. Ann Intern Med 2002;136:1-12.

4 Svensson B, Boonen A, Albertsson K, et al. Low-dose prednisolone in addition to the initial disease-modifying antirheumatic drug in patients with early active rheumatoid arthritis reduces joint destruction and increases the remission rate: a two-year randomized trial. Arthritis Rheum 2005;52:3360-70.

5 Wassenberg $S$, Rau R, Steinfeld P, et al. Very low-dose prednisolone in early rheumatoid arthritis retards radiographic progression over two years: a multicenter, double-blind, placebo-controlled trial. Arthritis Rheum 2005:52:3371-80.

6 Kirwan JR, Bijlsma JW, Boers M, et al. Effects of glucocorticoids on radiological progression in rheumatoid arthritis. Cochrane Database Syst Rev 2007:CD006356.

7 Bakker MF, Jacobs JW, Welsing PM, et al. Low-dose prednisone inclusion in a methotrexate-based, tight control strategy for early rheumatoid arthritis: a randomized trial. Ann Intern Med 2012;156:329-39.

8 Buttgereit F, da Silva JA, Boers M, et al. Standardised nomenclature for glucocorticoid dosages and glucocorticoid treatment regimens: current questions and tentative answers in rheumatology. Ann Rheum Dis 2002;61:718-22.

9 Hoes JN, Jacobs JW, Boers $M$, et al. EULAR evidence-based recommendations on the management of systemic glucocorticoid therapy in rheumatic diseases. Ann Rheum Dis 2007:66:1560-7.

10 Shekelle PG, Woolf SH, Eccles M, et al. Clinical guidelines: developing guidelines. Bmi 1999;318:593-6.

11 Roddy E, Zhang W, Doherty $M$, et al. Evidence-based clinical guidelines: a new system to better determine true strength of recommendation. J Eval Clin Pract 2006;12:347-52.

12 Choy EH, Kingsley GH, Khoshaba B, et al. A two year randomised controlled trial of intramuscular depot steroids in patients with established rheumatoid arthritis who have shown an incomplete response to disease modifying antirheumatic drugs. Ann Rheum Dis 2005;64:1288-93.

13 Choy EH, Smith CM, Farewell V, et al. Factorial randomised controlled trial of glucocorticoids and combination disease modifying drugs in early rheumatoid arthritis. Ann Rheum Dis 2008;67:656-63.

14 van Gestel AM, Laan RF, Haagsma CJ, et al. Oral steroids as bridge therapy in rheumatoid arthritis patients starting with parenteral gold. A randomized double-blind placebo-controlled trial. Br J Rheumatol 1995;34:347-51.

15 van Schaardenburg D, Valkema R, Dijkmans BA, et al. Prednisone treatment of elderly-onset rheumatoid arthritis. Disease activity and bone mass in comparison with chloroquine treatment. Arthritis Rheum 1995;38:334-42.

16 Verhoeven AC, Boers M, te Koppele JM, et al. Bone turnover, joint damage and bone mineral density in early rheumatoid arthritis treated with combination therapy including high-dose prednisolone. Rheumatology (Oxford) 2001:40:1231-7.

17 Bar-Meir S, Chowers Y, Lavy A, et al. Budesonide versus prednisone in the treatment of active Crohn's disease. The Israeli Budesonide Study Group. Gastroenterology 1998;115:835-40.

18 Bernstein CN, Seeger LL, Anton PA, et al. A randomized, placebo-controlled trial of calcium supplementation for decreased bone density in corticosteroid-using patients with inflammatory bowel disease: a pilot study. Aliment Pharmacol Ther 1996; 10:777-86.
19 Bootsma H, Spronk P, Derksen R, et al. Prevention of relapses in systemic lupus erythematosus. Lancet 1995;345:1595-9.

20 Boutsen Y, Jamart J, Esselinckx W, et al. Primary prevention of glucocorticoid-induced osteoporosis with intermittent intravenous pamidronate: a randomized trial. Calcif Tissue Int 1997;61:266-71.

21 Campieri M, Ferguson A, Doe W, et al. Oral budesonide is as effective as oral prednisolone in active Crohn's disease. The Global Budesonide Study Group. Gut 1997:41:209-14.

22 Caporali R, Cimmino MA, Ferraccioli G, et al. Prednisone plus methotrexate for polymyalgia rheumatica: a randomized, double-blind, placebo-controlled trial. Ann Intern Med 2004;141:493-500.

23 Chevalet $\mathrm{P}$, Barrier JH, Pottier $\mathrm{P}$, et al. A randomized, multicenter, controlled tria using intravenous pulses of methylprednisolone in the initial treatment of simple forms of giant cell arteritis: a one year followup study of 164 patients. J Rheumatol 2000;27:1484-91.

24 Choy EH, Kingsley GH, Corkill MM, et al. Intramuscular methylprednisolone is superior to pulse oral methylprednisolone during the induction phase of chrysotherapy. Br J Rheumatol 1993;32:734-9.

25 Corkill MM, Kirkham BW, Chikanza IC, et al. Intramuscular depot methylprednisolone induction of chrysotherapy in rheumatoid arthritis: a 24-week randomized controlled trial. Br J Rheumatol 1990;29:274-9.

26 Dasgupta B, Dolan AL, Panayi GS, et al. An initially double-blind controlled 96 week trial of depot methylprednisolone against oral prednisolone in the treatment of polymyalgia rheumatica. $\mathrm{Br} J$ Rheumatol 1998:37:189-95.

27 de Groot K, Harper L, Jayne DR, et al. Pulse versus daily oral cyclophosphamide for induction of remission in antineutrophil cytoplasmic antibody-associated vasculitis: a randomized trial. Ann Intern Med 2009;150:670-80.

28 EMPIRE Rheumatism Council: multi-centre controlled trial comparing cortisone acetate and acetyl salicylic acid in the long-term treatment of rheumatoid arthritis; results of three years' treatment. Ann Rheum Dis 1957;16:277-89.

29 Hoffman GS, Cid MC, Hellmann DB, et al. A multicenter, randomized, double-blind, placebo-controlled trial of adjuvant methotrexate treatment for giant cell arteritis. Arthritis Rheum 2002:46:1309-18.

30 Herrlinger KR, Witthoeft T, Raedler A, et al. Randomized, double blind controlled trial of subcutaneous recombinant human interleukin-11 versus prednisolone in active Crohn's disease. Am J Gastroenterol 2006;101:793-7.

31 Hernandez-Garcia C, Soriano C, Morado C, et al. Methotrexate treatment in the management of giant cell arteritis. Scand J Rheumatol 1994;23:295-8.

32 Hansen TM, Kryger $\mathrm{P}$, Elling $\mathrm{H}$, et al. Double blind placebo controlled trial of pulse treatment with methylprednisolone combined with disease modifying drugs in rheumatoid arthritis. Bmj 1990;301:268-70.

33 Guaydier-Souquieres G, Kotzki PO, Sabatier JP, et al. In corticosteroid-treated respiratory diseases, monofluorophosphate increases lumbar bone density: a double-masked randomized study. Osteoporos Int 1996:6:171-7.

34 Frediani B, Falsetti P, Baldi F, et al. Effects of 4-year treatment with once-weekly clodronate on prevention of corticosteroid-induced bone loss and fractures in patients with arthritis: evaluation with dual-energy $\mathrm{X}$-ray absorptiometry and quantitative ultrasound. Bone 2003;33:575-81.

35 Ferraccioli G, Casatta L, Bartoli E. Increase of bone mineral density and anabolic variables in patients with rheumatoid arthritis resistant to methotrexate after cyclosporin A therapy. J Rheumatol 1996;23:1539-42.

36 A comparison of prednisolone with aspirin on other analgesics in the treatment of rheumatold rthritis. Ann Rheum Dis 1959;18:173-88.

37 Wang HY, Cui TG, Hou FF, et al. Induction treatment of proliferative lupus nephritis with leflunomide combined with prednisone: a prospective multi-centre observational study. Lupus 2008;17:638-44.

38 Williams IA, Baylis EM, Shipley ME. A double-blind placebo-controlled trial of methylprednisolone pulse therapy in active rheumatoid disease. Lancet 1982;2:237-40.

39 Wanchu A, Suryanaryana BS, Sharma S, et al. High-dose prednisolone and bolus cyclophosphamide in interstitial lung disease associated with systemic sclerosis: a prospective open study. Int J Rheum Dis 2009;12:239-42.

40 Walters MT, Cawley MI. Combined suppressive drug treatment in severe refractory rheumatoid disease: an analysis of the relative effects of parenteral methylprednisolone, cyclophosphamide, and sodium aurothiomalate. Ann Rheum Dis 1988;47:924-9.

41 Verstappen SM, McCoy MJ, Roberts C, et al. Beneficial effects of a 3-week course of intramuscular glucocorticoid injections in patients with very early inflammatory polyarthritis: results of the STIVEA trial. Ann Rheum Dis 2010;69:503-9.

42 Verschueren P, Esselens G, Westhovens R. Daily practice effectiveness of a step-down treatment in comparison with a tight step-up for early rheumatoid arthritis. Rheumatology (Oxford) 2008;47:59-64.

43 van der Veen MJ, Dinant HJ, van Booma-Frankfort C, et al. Can methotrexate be used as a steroid sparing agent in the treatment of polymyalgia rheumatica and giant cell arteritis? Ann Rheum Dis 1996;55:218-23.

44 Tait TJ, Le Gallez P, Astbury C, et al. A clinical and biochemical assessment of methotrexate in rheumatoid arthritis. Clin Rheumatol 1994:13:75-9. 
45 Spiera RF, Mitnick HJ, Kupersmith M, et al. A prospective, double-blind, randomized, placebo controlled trial of methotrexate in the treatment of giant cell arteritis (GCA). Clin Exp Rheumatol 2001:19:495-501.

46 Silva F, Specks U, Kalra S, et al. Mycophenolate mofetil for induction and maintenance of remission in microscopic polyangiitis with mild to moderate renal involvement-a prospective, open-label pilot trial. Clin J Am Soc Nephrol 2010;5:445-53.

47 Shipley ME, Bacon PA, Berry $\mathrm{H}$, et al. Pulsed methylprednisolone in active early rheumatoid disease: a dose-ranging study. Br J Rheumatol 1988;27:211-14.

48 Sharada B, Kumar A, Kakker R, et al. Intravenous dexamethasone pulse therapy in diffuse systemic sclerosis. A randomized placebo-controlled study. Rheumatol Int 1994;14:91-4.

49 Salvarani C, Macchioni P, Manzini C, et al. Infliximab plus prednisone or placebo plus prednisone for the initial treatment of polymyalgia rheumatica: a randomized trial. Ann Intern Med 2007:146:631-9.

50 Sakamoto M, Shimizu K, lida S, et al. Osteonecrosis of the femoral head: a prospective study with MRI. J Bone Joint Surg Br 1997;79:213-19.

51 Rutgeerts $\mathrm{P}$, Lofberg $\mathrm{R}$, Malchow $\mathrm{H}$, et al. A comparison of budesonide with prednisolone for active Crohn's disease. N Engl J Med 1994;331:842-5.

52 Ribi $C$, Cohen $P$, Pagnoux $C$, et al. Treatment of polyarteritis nodosa and microscopic polyangiitis without poor-prognosis factors: A prospective randomized study of one hundred twenty-four patients. Arthritis Rheum 2010;62:1186-97.

53 Rhodes JM, Robinson R, Beales I, et al. Clinical trial: oral prednisolone metasulfobenzoate (Predocol) vs. oral prednisolone for active ulcerative colitis. Aliment Pharmacol Ther 2008;27:228-40.

54 Reid DM, Hughes RA, Laan RF, et al. Efficacy and safety of daily risedronate in the treatment of corticosteroid-induced osteoporosis in men and women: a randomized trial. European Corticosteroid-Induced Osteoporosis Treatment Study. J Bone Miner Res 2000;15:1006-13.

55 Pagnoux C, Mahr A, Hamidou MA, et al. Azathioprine or methotrexate maintenance for ANCA-associated vasculitis. N Engl J Med 2008:359:2790-803.

56 Nordborg E, Schaufelberger C, Andersson R, et al. The ineffectiveness of cyclical oral clodronate on bone mineral density in glucocorticoid-treated patients with giant-cell arteritis. J Intern Med 1997;242:367-71.

57 Mok CC, To CH, Ma KM. Changes in body composition after glucocorticoid therapy in patients with systemic lupus erythematosus. Lupus 2008;17:1018-22.

58 Messina OD, Barreira JC, Zanchetta JR, et al. Effect of low doses of deflazacort vs prednisone on bone mineral content in premenopausal rheumatoid arthritis. J Rheumatol 1992;19:1520-6.

59 Mazlumzadeh M, Hunder GG, Easley KA, et al. Treatment of giant cell arteritis using induction therapy with high-dose glucocorticoids: a double-blind, placebo-controlled, randomized prospective clinical trial. Arthritis Rheum 2006:54:3310-18.

60 Jover JA, Hernandez-Garcia C, Morado IC, et al. Combined treatment of giant-cell arteritis with methotrexate and prednisone. a randomized, double-blind, placebo-controlled trial. Ann Intern Med 2001;134:106-14.

61 Boers M, Nurmohamed MT, Doelman CJ, et al. Influence of glucocorticoids and disease activity on total and high density lipoprotein cholesterol in patients with rheumatoid arthritis. Ann Rheum Dis 2003:62:842-5.

62 Helliwell PS, Ibrahim G. Ethnic differences in responses to disease modifying drugs. Rheumatology (Oxford) 2003;42:1197-201.

63 van der Goes MC, Jacobs JW, Boers M, et al. Patient and rheumatologist perspectives on glucocorticoids: an exercise to improve the implementation of the European League Against Rheumatism (EULAR) recommendations on the management of systemic glucocorticoid therapy in rheumatic diseases. Ann Rheum Dis 2010;69:1015-21.

64 van der Meer V, Bakker MJ, van den Hout WB, et al. Internet-based self-management plus education compared with usual care in asthma: a randomized trial. Ann Intern Med 2009;151:110-20.

65 Janson SL, McGrath KW, Covington JK, et al. Individualized asthma self-management improves medication adherence and markers of asthma control. J Allergy Clin Immunol 2009:123:840-6.

66 Schacher $C$, Dhein Y, Munks-Lederer $C$, et al. [Evaluation of a structured outpatient education program for adult asthmatics]. Dtsch Med Wochenschr 2006;131:606-10.

67 Turner M0, Taylor D, Bennett R, et al. A randomized trial comparing peak expiratory flow and symptom self-management plans for patients with asthma attending a primary care clinic. Am J Respir Crit Care Med 1998:157:540-6.

68 Cote J, Cartier A, Robichaud P, et al. Influence on asthma morbidity of asthma education programs based on self-management plans following treatment optimization. Am J Respir Crit Care Med 1997;155:1509-14.

69 Gallefoss F, Bakke PS. How does patient education and self-management among asthmatics and patients with chronic obstructive pulmonary disease affect medication? Am J Respir Crit Care Med 1999;160:2000-5.

70 Abdelhamid E, Awad A, Gismallah A. Evaluation of a hospital pharmacy-based pharmaceutical care services for asthma patients. Pharmacy Practice 2008;6:25.

71 Demiralay R. The effects of asthma education on knowledge, behavior and morbidity in asthmatic patients. Turkish Journal of Medical Sciences 2004;34:319.

72 Effing $T$, Kerstjens $H$, van der Valk $P$, et al. (Cost)-effectiveness of self-treatment of exacerbations on the severity of exacerbations in patients with COPD: the COPE II study. Thorax 2009;64:956-62.
73 Rice $\mathrm{KL}$, Dewan $\mathrm{N}$, Bloomfield $\mathrm{HE}$, et al. Disease management program for chronic obstructive pulmonary disease: a randomized controlled trial. Am J Respir Crit Care Med 2010;182:890-6.

74 McGeoch GR, Willsman KJ, Dowson CA, et al. Self-management plans in the primary care of patients with chronic obstructive pulmonary disease. Respirology 2006:11:611-18.

75 McDonough RP, Doucette WR, Kumbera $\mathrm{P}$, et al. An evaluation of managing and educating patients on the risk of glucocorticoid-induced osteoporosis. Value Health 2005:8:24-31.

76 Trewin VF, Veitch GB. Patient sources of drug information and attitudes to their provision: a corticosteroid model. Pharm World Sci 2003;25:191-6.

77 Flemming TG, Kristensen LO. Quality of self-care in patients on replacement therapy with hydrocortisone. J Intern Med 1999;246:497-501.

78 Basak PY, Ozturk M, Baysal V. Assessment of information and education about topical corticosteroids in dermatology outpatient departments: experience from Turkey. J Eur Acad Dermatol Venereol 2003;17:652-8.

79 Boulet LP. Perception of the role and potential side effects of inhaled corticosteroids among asthmatic patients. Chest 1998;113:587-92.

80 Roskos SE, Wallace LS, Weiss BD. Readability of consumer medication information for intranasal corticosteroid inhalers. Am J Health Syst Pharm 2008;65:65-8.

81 Buchbinder R, Hall S, Grant G, et al. Readability and content of supplementary written drug information for patients used by Australian rheumatologists. Med $\mathrm{J}$ Aust 2001:174:575-8.

82 Hirsh D, Clerehan R, Staples M, et al. Patient assessment of medication information leaflets and validation of the Evaluative Linguistic Framework (ELF). Patient Educ Couns 2009;77:248-54

83 Tourinho TF, Capp E, Brenol JC, et al. Physical activity prevents bone loss in premenopausal women with rheumatoid arthritis: a cohort study. Rheumatol Int 2008:28:1001-7.

84 Madsen OR, Sorensen $\mathrm{OH}$, Egsmose C. Bone quality and bone mass as assessed by quantitative ultrasound and dual energyxray absorptiometry in women with rheumatoid arthritis: relationship with quadriceps strength. Ann Rheum Dis 2002;61:325-9.

85 World Health Organization. Global recommendations on physical activity for health. Geneva: World Health Organization, 2010.

86 World Health Organization. Preventing noncommunicable diseases in the workplace through diet and physical activity. Geneva: World Health Organization, 2008.

87 Ernst E. Exercise for female osteoporosis. A systematic review of randomised clinical trials. Sports Med 1998:25:359-68.

88 Grossman JM, Gordon R, Ranganath VK, et al. American College of Rheumatology 2010 recommendations for the prevention and treatment of glucocorticoid-induced osteoporosis. Arthritis Care Res (Hoboken) 2010;62:1515-26.

89 Saey D, Ribeiro F. Resistance training preserves skeletal muscle function in patients with COPD who are hospitalised with an acute exacerbation. J Physiother 2011;57:194

90 Braith RW, Magyari PM, Fulton MN, et al. Resistance exercise training and alendronate reverse glucocorticoid-induced osteoporosis in heart transplant recipients. J Heart Lung Transplant 2003;22:1082-90.

91 Braith RW, Welsch MA, Mills RM Jr., et al. Resistance exercise prevents glucocorticoid-induced myopathy in heart transplant recipients. Med Sci Sports Exerc 1998:30:483-9.

92 Braith RW, Mills RM, Welsch MA, et al. Resistance exercise training restores bone mineral density in heart transplant recipients. J Am Coll Cardiol 1996:28:1471-7.

93 Mitchell MJ, Baz MA, Fulton MN, et al. Resistance training prevents vertebral osteoporosis in lung transplant recipients. Transplantation 2003;76:557-62.

94 Kanis JA, Borgstrom F, De Laet C, et al. Assessment of fracture risk. Osteoporos Int 2005;16:581-9.

95 Tang BM, Eslick GD, Nowson C, et al. Use of calcium or calcium in combination with vitamin $D$ supplementation to prevent fractures and bone loss in people aged 50 years and older: a meta-analysis. Lancet 2007;370:657-66.

96 Homik J, Suarez-Almazor ME, Shea B, et al. Calcium and vitamin D for corticosteroid-induced osteoporosis. Cochrane Database Syst Rev 2000:CD000952.

97 Hakkinen A, Sokka T, Kautiainen $H$, et al. Sustained maintenance of exercise induced muscle strength gains and normal bone mineral density in patients with early rheumatoid arthritis: a 5 year follow up. Ann Rheum Dis 2004;63:910-16.

98 Schoenfeld SR, Kasturi S, Costenbader KH. The epidemiology of atherosclerotic cardiovascular disease among patients with SLE: a systematic review. Semin Arthritis Rheum. 19 Feb 2013 [Epub ahead of print] doi: 10.1016/j. semarthrit.2012.12.002

99 Davis JM 3rd, Maradit Kremers H, Crowson CS, et al. Glucocorticoids and cardiovascular events in rheumatoid arthritis: a population-based cohort study. Arthritis Rheum 2007;56:820-30.

100 Huscher D, Thiele K, Gromnica-Ihle E, et al. Dose-related patterns of glucocorticoid-induced side effects. Ann Rheum Dis 2009;68:1119-24.

101 Dixon WG, Kezouh A, Bernatsky S, et al. The influence of systemic glucocorticoid therapy upon the risk of non-serious infection in older patients with rheumatoid arthritis: a nested case-control study. Ann Rheum Dis 2011;70:956-60.

102 Homik J, Cranney A, Shea B, et al. Bisphosphonates for steroid induced osteoporosis. Cochrane Database Syst Rev 2000:CD001347. 
103 de Nijs RN, Jacobs JW, Algra A, et al. Prevention and treatment of glucocorticoid-induced osteoporosis with active vitamin D3 analogues: a review with meta-analysis of randomized controlled trials including organ transplantation studies. Osteoporos Int 2004;15:589-602.

104 Amin S, Lavalley MP, Simms RW, et al. The comparative efficacy of drug therapies used for the management of corticosteroid-induced osteoporosis: a meta-regression. J Bone Miner Res 2002;17:1512-26.

105 Richy F, Schacht E, Bruyere O, et al. Vitamin D analogs versus native vitamin D in preventing bone loss and osteoporosis-related fractures: a comparative meta-analysis. Calcif Tissue Int 2005;76:176-86.

106 van Staa TP, Leufkens HG, Cooper C. The epidemiology of corticosteroid-induced osteoporosis: a meta-analysis. Osteoporos Int 2002;13:777-87.

107 van Staa TP. The pathogenesis, epidemiology and management of glucocorticoid-induced osteoporosis. Calcif Tissue Int 2006;79:129-37.

108 Keller C, Hafstrom I, Svensson B. Bone mineral density in women and men with early rheumatoid arthritis. Scand J Rheumatol 2001;30:213-20.

109 Shenstone BD, Mahmoud A, Woodward R, et al. Longitudinal bone mineral density changes in early rheumatoid arthritis. Br J Rheumatol 1994;33:541-5.

110 Book C, Karlsson M, Akesson K, et al. Disease activity and disability but probably not glucocorticoid treatment predicts loss in bone mineral density in women with early rheumatoid arthritis. Scand J Rheumatol 2008;37:248-54.

111 Forslind K, Keller C, Svensson B, et al. Reduced bone mineral density in early rheumatoid arthritis is associated with radiological joint damage at baseline and after 2 years in women. J Rheumatol 2003;30:2590-6.

112 Gough AK, Lilley J, Eyre S, et al. Generalised bone loss in patients with early rheumatoid arthritis. Lancet 1994;344:23-7.

113 Lodder MC, de Jong Z, Kostense PJ, et al. Bone mineral density in patients with rheumatoid arthritis: relation between disease severity and low bone mineral density. Ann Rheum Dis 2004;63:1576-80.

114 van Staa TP, Geusens P, Pols HA, et al. A simple score for estimating the long-term risk of fracture in patients using oral glucocorticoids. Qjm 2005;98:191-8.

115 Kanis JA, McCloskey EV, Johansson $\mathrm{H}$, et al. Case finding for the management of osteoporosis with FRAX-assessment and intervention thresholds for the UK. Osteoporos Int 2008;19:1395-408.

116 McCloskey E, Kanis JA. FRAX updates 2012. Curr Opin Rheumatol 2012;24:554-60.

117 Kanis JA, Johansson $\mathrm{H}$, Oden A, et al. Guidance for the adjustment of FRAX according to the dose of glucocorticoids. Osteoporos Int 2011;22:809-16.

118 Marik PE, Varon J. Requirement of perioperative stress doses of corticosteroids: a systematic review of the literature. Arch Surg 2008;143:1222-6.

119 Yong SL, Marik P, Esposito M, et al. Supplemental perioperative steroids for surgical patients with adrenal insufficiency. Cochrane Database Syst Rev 2009:CD005367.

120 Cooper MS, Stewart PM. Corticosteroid insufficiency in acutely ill patients. N Engl J Med 2003;348:727-34.

121 Ackerman GL, Nolsn CM. Adrenocortical responsiveness after alternate-day corticosteroid therapy. N Engl J Med 1968;278:405-9.

122 Schlaghecke R, Kornely E, Santen RT, et al. The effect of long-term glucocorticoid therapy on pituitary-adrenal responses to exogenous corticotropin-releasing hormone. N Engl J Med 1992;326:226-30.

123 Eizenga WH, Hakvoort L, Dubbeld P, et al. [Dutch College of General Practitioner's practice guideline on polymyalgia rheumatica and temporal arteritis]. Ned Tijdschr Geneeskd 2010;154:A1919.

124 de Vries M, Berendsen AJ, Bosveld HE, et al. COPD exacerbations in general practice: variability in oral prednisolone courses. BMC Fam Pract 2012;13:3.

125 Da Silva JA, Jacobs JW, Kirwan JR, et al. Safety of low dose glucocorticoid treatment in rheumatoid arthritis: published evidence and prospective trial data. Ann Rheum Dis 2006:65:285-93.

126 Saag KG, Koehnke R, Caldwell JR, et al. Low dose long-term corticosteroid therapy in rheumatoid arthritis: an analysis of serious adverse events. Am J Med 1994;96:115-23.

127 Wolfe F, Caplan L, Michaud K. Treatment for rheumatoid arthritis and the risk of hospitalization for pneumonia: associations with prednisone, disease-modifying antirheumatic drugs, and anti-tumor necrosis factor therapy. Arthritis Rheum 2006;54:628-34.

128 Chung $\mathrm{CP}$, Oeser A, Solus JF, et al. Inflammation-associated insulin resistance: differential effects in rheumatoid arthritis and systemic lupus erythematosus define potential mechanisms. Arthritis Rheum 2008;58:2105-12.

129 Dessein $\mathrm{PH}$, Joffe BI. Insulin resistance and impaired beta cell function in rheumatoid arthritis. Arthritis Rheum 2006:54:2765-75.

130 den Uyl D, van Raalte DH, Nurmohamed MT, et al. Metabolic effects of high-dose prednisolone treatment in early rheumatoid arthritis: Diabetogenic effects and inflammation reduction on the balance. Arthritis Rheum 2011.

131 Panthakalam S, Bhatnagar D, Klimiuk P. The prevalence and management of hyperglycaemia in patients with rheumatoid arthritis on corticosteroid therapy. Scott Med J 2004;49:139-41.

132 Ha Y, Lee KH, Jung S, et al. Glucocorticoid-induced diabetes mellitus in patients with systemic lupus erythematosus treated with high-dose glucocorticoid therapy. Lupus 2011;20:1027-34
133 Peters MJ, Vis M, van Halm VP, et al. Changes in lipid profile during infliximab and corticosteroid treatment in rheumatoid arthritis. Ann Rheum Dis 2007:66:958-61.

134 Klarenbeek NB, van der Kooij SM, Huizinga TJ, et al. Blood pressure changes in patients with recent-onset rheumatoid arthritis treated with four different treatment strategies: a post hoc analysis from the BeSt trial. Ann Rheum Dis 2010:69:1342-5.

135 Imai Y, Abe K, Sasaki S, et al. Exogenous glucocorticoid eliminates or reverses circadian blood pressure variations. J Hypertens 1989;7:113-20.

136 Georgiadis AN, Papavasiliou EC, Lourida ES, et al. Atherogenic lipid profile is a feature characteristic of patients with early rheumatoid arthritis: effect of early treatment-a prospective, controlled study. Arthritis Res Ther 2006;8:R82.

137 Peters MJ, Symmons DP, McCarey D, et al. EULAR evidence-based recommendations for cardiovascular risk management in patients with rheumatoid arthritis and other forms of inflammatory arthritis. Ann Rheum Dis 2010;69:325-31.

138 Garcia Rodriguez LA, Hernandez-Diaz S. The risk of upper gastrointestinal complications associated with nonsteroidal anti-inflammatory drugs, glucocorticoids, acetaminophen, and combinations of these agents. Arthritis Res 2001:3:98-101.

139 Piper JM, Ray WA, Daugherty JR, et al. Corticosteroid use and peptic ulcer disease: role of nonsteroidal anti-inflammatory drugs. Ann Intern Med 1991;114:735-40.

140 van Everdingen AA, Siewertsz van Reesema DR, Jacobs JW, et al. The clinical effect of glucocorticoids in patients with rheumatoid arthritis may be masked by decreased use of additional therapies. Arthritis Rheum 2004;51:233-8.

141 Widdifield J, Bernatsky S, Paterson JM, et al. Serious infections in a population-based cohort of 86,039 seniors with rheumatoid arthritis. Arthritis Care Res (Hoboken) 2013:65:353-61.

142 Dixon WG, Abrahamowicz M, Beauchamp ME, et al. Immediate and delayed impact of oral glucocorticoid therapy on risk of serious infection in older patients with rheumatoid arthritis: a nested case-control analysis. Ann Rheum Dis 2012;71:1128-33.

143 Crowson CS, Hoganson DD, Fitz-Gibbon PD, et al. Development and validation of a risk score for serious infection in patients with rheumatoid arthritis. Arthritis Rheum 2012;64:2847-55.

144 Belard E, Semb S, Ruhwald M, et al. Prednisolone treatment affects the performance of the QuantiFERON gold in-tube test and the tuberculin skin test in patients with autoimmune disorders screened for latent tuberculosis infection. Inflamm Bowel Dis 2011;17:2340-9.

145 van Assen S, Agmon-Levin N, Elkayam 0, et al. EULAR recommendations for vaccination in adult patients with autoimmune inflammatory rheumatic diseases. Ann Rheum Dis 2011;70:414-22.

146 Tripathi RC, Parapuram SK, Tripathi BJ, et al. Corticosteroids and glaucoma risk. Drugs Aging 1999;15:439-50.

147 Garbe E, LeLorier J, Boivin JF, et al. Risk of ocular hypertension or open-angle glaucoma in elderly patients on oral glucocorticoids. Lancet 1997; 350:979-82.

148 van der Goes MC, Jacobs JW, Boers M, et al. Monitoring adverse events of low-dose glucocorticoid therapy: EULAR recommendations for clinical trials and daily practice. Ann Rheum Dis 2010;69:1913-19.

149 Hernandez-Rodriguez J, Cid MC, Lopez-Soto A, et al. Treatment of polymyalgia rheumatica: a systematic review. Arch Intern Med 2009;169:1839-50.

150 Salvarani C, Cantini F, Hunder GG. Polymyalgia rheumatica and giant-cell arteritis. Lancet 2008:372:234-45.

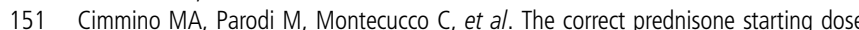
in polymyalgia rheumatica is related to body weight but not to disease severity. BMC Musculoskelet Disord 2011;12:94.

152 Mahr AD, Jover JA, Spiera RF, et al. Adjunctive methotrexate for treatment of giant cell arteritis: an individual patient data meta-analysis. Arthritis Rheum 2007:56:2789-97.

153 Ferraccioli G, Salaffi F, De Vita S, et al. Methotrexate in polymyalgia rheumatica: preliminary results of an open, randomized study. J Rheumatol 1996; 23:624-8

154 De Silva M, Hazleman BL. Azathioprine in giant cell arteritis/polymyalgia rheumatica: a double-blind study. Ann Rheum Dis 1986;45:136-8.

155 Hoffman GS, Cid MC, Rendt-Zagar KE, et al. Infliximab for maintenance of glucocorticosteroid-induced remission of giant cell arteritis: a randomized trial. Ann Intern Med 2007;146:621-30.

156 Schaufelberger C, Mollby H, Uddhammar A, et al. No additional steroid-sparing effect of cyclosporine A in giant cell arteritis. Scand I Rheumatol 2006; 35:327-9.

157 Martinez-Taboada VM, Rodriguez-Valverde V, Carreno L, et al. A double-blind placebo controlled trial of etanercept in patients with giant cell arteritis and corticosteroid side effects. Ann Rheum Dis 2008;67:625-30.

158 Feinstein AR. An additional basic science for clinical medicine: II. The limitations of randomized trials. Ann Intern Med 1983;99:544-50.

159 Smith GC, Pell JP. Parachute use to prevent death and major trauma related to gravitational challenge: systematic review of randomised controlled trials. BMJ 2003:327:1459-61. 